\title{
Intraglandular transplantation of adipose-derived stem cells combined with platelet-rich fibrin extract for the treatment of irradiation-induced salivary gland damage
}

\author{
ZHIFA WANG ${ }^{1,2 *}$, HONGYAN XING $^{3 *}$, HANQING HU $^{4 *}$, TAIQIANG DAI ${ }^{2}$, YAN WANG ${ }^{2}$, \\ ZHIJIN $\mathrm{LI}^{2}$, RAN AN ${ }^{5}$, HAIYAN XU ${ }^{5}$, YANPU LIU ${ }^{2}$ and BIN LIU ${ }^{5}$
}

\begin{abstract}
${ }^{1}$ Department of Stomatology, Guangzhou General Hospital of Guangzhou Command, Guangzhou, Guangdong 510010;
${ }^{2}$ Department of Oral and Maxillofacial Surgery, State Key Laboratory of Military Stomatology, School of Stomatology, The Fourth Military Medical University, Xi'an, Shaanxi 710032; ${ }^{3}$ Department of Stomatology, Xinzhou 2nd People's Hospital, Xinzhou, Shaanxi 034100; ${ }^{4}$ Department of Stomatology, The 94th Hospital of PLA, Nanchang, Jiangxi 330002;

${ }^{5}$ Laboratory Animal Center, State Key Laboratory of Military Stomatology, School of Stomatology, The Fourth Military Medical University, Xi'an, Shaanxi 710032, P.R. China
\end{abstract}

Received December 7, 2015; Accepted December 19, 2016

DOI: $10.3892 /$ etm.2017.5497

\begin{abstract}
The aim of the present study was to determine the effect of adipose-derived mesenchymal stem cells (ADSCs) combined with heterologous platelet-rich fibrin extract (PRFe) on irradiation-induced salivary gland (SG) damage. ADSCs were isolated from $\mathrm{C} 3 \mathrm{H}$ mice, whereas $\mathrm{PRFe}$ was obtained from New Zealand rabbits. Twelve weeks post irradiation, the ADSCs or PRFe or their combination were transplanted into the submandibular glands of $\mathrm{C} 3 \mathrm{H}$ mice with irradiation-induced damage. The salivary flow rate (SFR) was determined and histopathological analysis was performed at 12 weeks post transplantation. Immunofluorescence, microvessel density measurements and transmission electron microscopy were performed to assess $\alpha$-amylase (AMY) production, apoptosis and microstructural changes in the cells. The administration of ADSCs combined with PRFe increased the SFR at 12 weeks post transplantation, whereas ADSCs alone or PRFe alone failed to do so. The ADSCs+PRFe-treated, irradiated
\end{abstract}

Correspondence to: Professor Bin Liu, Laboratory Animal Center, State Key Laboratory of Military Stomatology, School of Stomatology, The Fourth Military Medical University, 145 West Changle Road, Xi'an, Shaanxi 710032, P.R. China

E-mail:kqyljd_liu@126.com

Professor Yanpu Liu, Department of Oral and Maxillofacial Surgery, State Key Laboratory of Military Stomatology, School of Stomatology, The Fourth Military Medical University, 145 West Changle Road, Xi'an, Shaanxi 710032, P.R. China

E-mail: liuyanpu@fmmu.edu.cn

*Contributed equally

Key words: irradiation, adipose-derived stem cells, platelet-rich fibrin extract, salivary gland
SGs had fewer damaged and atrophied acinar cells, higher AMY levels and an increased microvessel density compared with the untreated irradiated SGs. Moreover, SG tissue from the ADSCs+PRFe group also showed decreased apoptotic and increased proliferative activity compared to that from the irradiated group. In conclusion, ADSCs or PRFe alone did not restore permanent, irradiation-induced damage of SG tissue when used alone, but when used together, they provided effective treatment outcomes.

\section{Introduction}

The main function of salivary glands (SGs) is to secret saliva, which is essential for the maintenance of oral health. Saliva is required for lubrication, digestion, perception of taste, protection against noxious materials and microorganisms and for the maintenance of immune homeostasis (1). Reduction in the secretion of saliva inevitably causes dry mouth and a series of accompanying complications, including secondary rampant caries, chewing and swallowing disorders, loss of the sense of taste and oral mucous inflammation, which may significantly depress the quality of life of affected individuals (2).

Approximately 500,000 novel cases of head and neck cancer develop worldwide annually. Amongst them, the vast majority of advanced patients require radiotherapy, either alone or in combination with other treatments, such as chemotherapy, as a primary or adjuvant mode of treatment following surgery. This inevitably causes damage to the SGs. Approximately $40 \%$ of the patients who receive radiotherapy develop salivary hypofunction or xerostomia (3), and suffer from severe pain and other complications, leading to the termination of cancer treatment in certain cases. Current treatment strategies are limited to conservative care based on sialagogues or salivary substitutes (4). However, to date, no satisfactory treatment is available to address this fundamental issue.

A growing number of therapeutic strategies have been devised to recover or rehabilitate damaged SGs, including 
gene therapy $(5,6)$, construction of tissue-engineered artificial SGs $(7-10)$, re-implantation of autologous SG cells $(11,12)$ and stem cell therapy $(13,14)$. The study of duct-ligated SGs has confirmed the presence of stem/progenitor cells in SGs, which can differentiate into functional hepatocytes and $\beta$-cells (15). Moreover, intraglandular transplantation of a small amount of SG stem cells (c-kit ${ }^{+}$cells) has resulted in the long-term recovery of irradiation-induced damaged SG morphology and function (11). Besides, bone marrow-derived stem cells (BMSCs) and their soluble intracellular contents (termed as 'BM soup') have also been used for the treatment of irradiation-induced SG hypofunction $(14,16)$. Adipose tissue-derived stem cells (ADSCs) are another type of pluripotent adult stem cells that can differentiate into bone, cartilage, fat and nerve cells. Furthermore, they can easily be obtained with minimal invasion and are readily available, as the density of mesenchymal stem cells (MSCs) is much higher in adipose tissues than in bone marrow (17). Therefore, ADSCs have been used in tissue engineering and regenerative medicine with a proven ability to prevent irradiation-induced SG damage $(13,18)$. However, to the best of our knowledge, there have been no studies on treatments for permanent SG damage induced by radiotherapy.

Platelet-rich fibrin (PRF), a second-generation platelet-rich concentrate, contains a variety of growth factors that are slowly and continuously released (19). During the centrifugation process of PRF production, the supernatant, referred to as acellular or platelet-poor plasma (PPP), is also known to promote cell proliferation $(19,20)$. A study by Liu et al (21) has corroborated that PRF can improve the survival rate of transplanted adipose tissue and increase its angiogenic properties. The study also reported that PRF can release growth factors for at least 2 weeks in vitro, thereby suggesting the presence of a variety of growth factors in the PRF extract (PRFe) obtained from PRF immersed in PPP (21).

The purpose of the present study was to determine whether the administration of ADSCs combined with PRFe is more effective than ADSCs alone for the treatment of radiation-induced SG damage. At 3 months post irradiation, ADSCs, PRFe or ADSCs combined with PRFe were transplanted into the submandibular glands of $\mathrm{C} 3 \mathrm{H}$ mice with permanent $\mathrm{SG}$ damage induced by radiotherapy. Functional and morphological changes in the SGs were assessed using transmission electron microscopy (TEM) and immunofluorescence in order to determine the salivary flow rate (SFR), histopathological changes and microvessel density at 3 months post transplantation.

\section{Materials and methods}

Ethics statement. The protocols of the present study were reviewed and approved by the Institutional Animal Care and Use Committee at the Fourth Military Medical University (Xi'an, China). Animals were cared for according to established institutional guidelines and all efforts were made to minimize suffering. Surgeries were performed under anesthesia with xylazine $(10 \mathrm{mg} / \mathrm{kg}$; Meridian Life Science, Inc., Memphis, $\mathrm{TN}$, USA) premedication and an intraperitoneal injection of ketamine (110 mg/kg; Meridian Life Science, Inc.).

Irradiation-induced $S G$ damage in $\mathrm{C} 3 \mathrm{H}$ mice. A total of 80 8-12-week old female $\mathrm{C} 3 \mathrm{H}$ mice (weight, 28-34 g) were purchased from Vital River Laboratory Animal Technology Co., Ltd. (Beijing, China). The mice were maintained in a specific pathogen-free, microisolated environment (temperature, $18-29^{\circ} \mathrm{C}$; humidity, $50-80 \%$ ) with a $12 \mathrm{~h} \mathrm{light/dark}$ cycle at the Laboratory Animal Center of the School of Stomatology (the Fourth Military Medical University, Xi'an, China) and were provided with a standard pellet diet along with free access to sterilized water.

The animals were anesthetized by intraperitoneal injection of $50 \mathrm{mg} / \mathrm{kg}$ sodium pentobarbital (Sigma-Aldrich; Merck KGaA, Darmstadt, Germany) and irradiated with a single dose of $18 \mathrm{~Gy}$ at a focus-to-skin distance of $100 \mathrm{~cm}$, using a 4 MV X-ray from a linear accelerator (Mevatron MD; Siemens Medical Laboratories, Inc., Munich, Germany). The mice were locally irradiated in the head and neck region, including the SGs, while the body was protected by a $12 \mathrm{~mm}$-thick lead block. This radiation dose is known to induce sufficient damage without compromising the general health of the animal and results in permanent, irreversible salivary dysfunction within 6 months of exposure (22).

Preparation of ADSCs. Mouse ADSCs were isolated and expanded according to methods described previously (21), with minor modifications. In brief, the inguinal fat pads were obtained from 20 8-week-old, male C3H mice under general anesthesia by intraperitoneal injection of $50 \mathrm{mg} / \mathrm{kg}$ sodium pentobarbital under sterile conditions, following which mice were sacrificed with an overdose of 3\% isoflurane gas (Beijing Guochengruitai Science \& Technology Co., Ltd, Beijing, China). Following the removal of the thin fascia and blood vessels covering the adipose tissue, the pads were minced into small fragments of $\sim 1 \mathrm{~mm}^{3}$ and enzymatically dissociated with $0.2 \%$ collagenase type I (Sigma-Aldrich; Merck KGaA) on a shaking table with continuous agitation for $40 \mathrm{~min}$ at $37^{\circ} \mathrm{C}$ to separate the stromal cell fraction from adipocytes. The stromal cell fraction was then filtered through a $100-\mu \mathrm{m}$ cell strainer (BD Biosciences, San Jose, CA, USA) and centrifuged at $1,200 \mathrm{xg}$ for $5 \mathrm{~min}$ at $26^{\circ} \mathrm{C}$. The cell pellet was resuspended into Dulbecco's modified Eagle's medium-F12 (DMEM-F12; Gibco, Thermo Fisher Scientific, Inc., Waltham, MA, USA) containing 10\% fetal bovine serum (FBS; Gibco, Thermo Fisher Scientific, Inc.), 0.272 g/l L-glutamine (Sigma-Aldrich; Merck KGaA), and $2 \%$ antibiotics $(200 \mathrm{mg} / \mathrm{ml}$ penicillin and $200 \mathrm{mg} / \mathrm{ml}$ streptomycin; Gibco, Thermo Fisher Scientific, Inc.). Next, the cell suspension was plated in $100-\mathrm{mm}$ cell culture dishes and standard medium was added to reach a volume of $10 \mathrm{ml}$. The cells were incubated at $37^{\circ} \mathrm{C}$ in an atmosphere containing $5 \% \mathrm{CO}_{2}$ with $100 \%$ humidity. After 3 days, the medium and all floating cells were removed and fresh medium was added to the remaining adherent cells, which were considered as the ADSCs. The medium was replaced every 3 days until the cells reached confluence, following which they were subcultured at a ratio of 1:3. ADSCs from the third passage were used in the present study. In order to identify the characteristics of the cultured cells, flow cytometry (FACSCalibur; BD Biosciences) as well as tests to examine the pluripotent plasticity of stem cells, including osteogenic and adipogenic differentiation, were performed. Briefly, cells were labeled and incubated with mouse monoclonal antibodies against CD29 (cat. no. ab95623; 1:200), CD31 (cat. 
no. ab24590; 1:200), and CD34 (cat. no. ab187282; 1:200) (all from Abcam, Cambridge, MA, USA) at $4^{\circ} \mathrm{C}$ for $30 \mathrm{~min}$, with an isotype-identical antibody ( $\mathrm{IgG})$ as a control (ab37355; 1:200; Abcam), and were subsequently incubated with fluorescein isothiocyanate-labeled goat anti-mouse IgG antibody in the dark at $4^{\circ} \mathrm{C}$ for $30 \mathrm{~min}$, PBS washed, and analyzed on a BD FACSCalibur. For osteogenic differentiation, ADSCs were cultured at $37^{\circ} \mathrm{C}$ in osteogenic media for three weeks, and osteogenesis was subsequently assessed using Alizarin red staining. For adipogenic differentiation, ADSCs were cultured at $37^{\circ} \mathrm{C}$ in adipogenic media for two weeks, and adipogenesis was assessed by Oil-Red-O staining for the presence of lipid vacuoles using light microscopy (DX51; Olympus Corporation, Tokyo, Japan). Furthermore, in order to meet the requirements for transplantation of huge numbers of ADSCs, a 3-D dynamic culture system based on the use of a rotating cell culture system bioreactor (RCCS; Synthecon Inc., Houston, TX, USA) was used to culture and expand stem cells according to a previously described method $(23,24)$, with minor modifications. In brief, cytodex-3 microcarrier beads (GE Healthcare, Chalfont, UK) were soaked in 0.1 M PBS (Sigma-Aldrich; Merck KGaA) overnight and then washed three times in PBS, followed by autoclaving at $115^{\circ} \mathrm{C}$ for $30 \mathrm{~min}$. Subsequently, the beads were washed twice using serum-free DMEM-F12, placed in DMEM-F12 containing 10\% FBS complete media and stored at $4^{\circ} \mathrm{C}$. The ADSCs were inoculated at a density of $1 \times 10^{5} / \mathrm{ml}$ with cytodex-3 $(5 \mathrm{mg} / \mathrm{ml})$, loaded into the rotating cell culture system and rotated in an incubator containing $5 \%$ $\mathrm{CO}_{2}$ at $37^{\circ} \mathrm{C}$. For the control group, stem cells were seeded in a 24 -well culture plate at a density of $1 \times 10^{5} / \mathrm{ml}$. The stem cells were labeled using the fluorescent reactive dye DiI (Molecular Probes; Thermo Fisher Scientific, Inc.) to display adhesion and growth of the cells on the cytodex-3 beads, and the microstructure was observed by scanning electron microscopy (SEM; S-4800, Hitachi, Tokyo, Japan).

Preparation of PRFe from New Zealand rabbits. A total of 6 3-month-old male New Zealand rabbits (mean weight, $2.5 \mathrm{~kg}$ ) were obtained from the animal holding unit of the Fourth Military Medical University. The rabbits were housed at $18-29^{\circ} \mathrm{C}$ with $50-80 \%$ humidity and a $12 \mathrm{~h}$ light/dark cycle at the Laboratory Animal Center of the School of Stomatology. Rabbits were provided with a standard pellet diet with free access to sterilized water. The preparation of PRF was performed as described previously (21), with minor modifications. In brief, $10 \mathrm{ml}$ of blood was collected from each rabbit in 10-ml dried microcentrifuge tubes without anticoagulant and immediately centrifuged for $10 \mathrm{~min}$ at $1,200 \mathrm{x}$ g at $26^{\circ} \mathrm{C}$. The centrifuged product consisted of three layers; the PRF clot was located in the middle of the tube, just between the red corpuscles at the bottom and PPP on top. The acellular plasma was collected in a 4-ml microcentrifuge tube for further use. The PRF clot was harvested with tweezers and, using soft compression for $10 \mathrm{sec}$, gently pressed onto a membrane, between two sterile pieces of gauze, in order to keep the membrane wet. The obtained PRF membranes were cut into small fragments in sterile dishes and then immersed into microcentrifuge tubes containing acellular plasma. Finally, in order to release the growth factors, the tubes were placed on a shaking table with continuous agitation at $37^{\circ} \mathrm{C}$ for 1 week.
The supernatant, which was the PRFe, was harvested for further transplantation.

Transplantation. The irradiation-induced, SG-damaged $\mathrm{C} 3 \mathrm{H}$ mice $(n=40)$ were randomly divided into the following groups consisting of 10 mice each: IR+ADSCs+PRFe treatment group (received ADSCs in combination with PRFe at 12 weeks post irradiation); IR+ADSC treatment group (received ADSCs alone at 12 weeks post irradiation); IR+PRFe treatment group (received PRFe alone at 12 weeks post irradiation); and IR+PBS negative control group (an irradiated/untreated group that was injected with $100 \mu \mathrm{l}$ PBS). A fifth, non-irradiated group (normal, positive control) comprising 10 mice, was also included in the study. Mice were anesthetized via intraperitoneal injection of $50 \mathrm{mg} / \mathrm{kg}$ sodium pentobarbital, and subsequently ADSCs, alone or in combination with PRFe, and PRFe alone were injected through the capsule of both submandibular glands. Two injections of $50 \mu \mathrm{l}$ each per gland were given, which contained $2 \times 10^{5}$ ADSCs. In the IR+ADSCs group, $2 \times 10^{5}$ cells were suspended in $100 \mu \mathrm{l} \mathrm{PBS}$, whereas in the IR+ADSCs+PRF group, $2 \times 10^{5}$ cells were suspended in $100 \mu \mathrm{l}$ PRFe supernatant. Only $100 \mu \mathrm{l}$ PRFe was injected into the mice of the IR+PRFe group. This infusion was repeated weekly for three consecutive weeks.

Furthermore, in order to confirm the successful injection of ADSCs in the submandibular gland, the stem cells were labeled using the fluorescent reactive dye DiI. Four weeks after intraglandular injection, the mice were sacrificed by cervical dislocation and the submandibular glands were harvested and snap frozen in liquid nitrogen. Frozen SG tissue sections were analyzed by fluorescence microscopy for detection of DiI-positive stem cells in the SGs (25).

\section{Morphological and functional evaluation}

Salivary flow rate. Salivary secretory function was determined by measuring the SFR at 12 weeks after transplantation. Saliva was collected from the floor of the mouth using a micropipette for a period of 5 min after stimulation with an intraperitoneal injection of pilocarpine $(2 \mathrm{mg} / \mathrm{kg}$; Toronto Research Chemicals, Inc., North York, ON, Canada). The collected saliva was placed in a pre-weighed 1.5-ml microcentrifuge tube and the SFR $(\mu 1 / \mathrm{min})$ was calculated by dividing the weight (mg) of saliva collected by the duration of collection (min) (saliva was assumed to have a specific gravity of $1 \mathrm{mg} / \mathrm{ml}$ ).

Measurement of gland and body weight. At 12 weeks after transplantation, the gland and body weights of the mice were measured, followed by saliva collection and, finally, sacrifice by cervical dislocation. The submandibular glands were harvested and the surrounding fat and connective tissues were removed. The weight of the harvested glands was individually determined prior to fixation in $10 \%$ neutral formalin buffer and embedding in paraffin.

Histological and immunohistochemical evaluation of changes in the structure and function of acinar cells. Following deparaffinization and rehydration, the tissue sections were analyzed by hematoxylin and eosin (H\&E) staining. The quantification of acinar cells was performed by counting the number of cells using light microscopy (DX51; Olympus Corporation) at 
x200 magnification. The assessments were performed in three randomly selected sections by two independent observers.

Moreover, Periodic acid-Schiff (PAS; Sigma-Aldrich; Merck KGaA) staining was also performed to evaluate the changes. The ratio of the surface area occupied by PAS-positive cells to the total measured area was quantified in five random fields under x400 magnification using a light microscope. The assessments were performed in three randomly selected sections by two independent observers using the Image J software (National Institutes of Health, Bethesda, MD, USA).

The function of acinar cells was studied by measuring $\alpha$-amylase (AMY) production (Abcam) using immunohistochemistry in SG tissues as previously described $(22,26)$. The percentage of surface area occupied by AMY-containing acinar cells was determined by densitometry using light microscopy at x400 magnification. Three sections were prepared for each gland and at least three fields per section were examined by two blinded investigators using Metamorph software (Version 7.6.4; Molecular Devices Corp., Sunnyvale, CA, USA).

CD31 staining for microvessel density analysis. Microvessel density analysis was performed using Weidner's method (27), with minor modifications. Following de-paraffinization and rehydration, tissue sections were analyzed by immunohistochemical staining for CD31. As previously described (Abcam) (26). At x100 magnification, a region of dense, regenerated blood vessels was selected (hot spot), and cells with brown (positive) staining were then identified within this 'hot spot' at x200 magnification. Each positively stained cell or cell cluster was regarded as a newly formed blood vessel, while the positively stained red blood cells in the vessel cava were excluded. If the size of a vessel cavum was larger than that of eight blood cells, it was not considered as a newly formed blood vessel and was excluded. Data obtained from five 'hot spots', examined at x200 magnification using the Image $\mathbf{J}$ software (National Institutes of Health), were statistically analyzed (21).

TEM. The specimens were fixed in $2.5 \%$ glutaraldehyde solution for $12 \mathrm{~h}$ and post-fixed in $1 \%$ osmium tetroxide for 2 h (Sigma-Aldrich; Merck KGaA). Following dehydration and embedding in epoxy resin, the specimens were cut into semi-thin $(2 \mu \mathrm{m})$, longitudinal sections and examined with a TEM (JEM-1230; Jeol, Tokyo, Japan).

Detection of apoptosis. Apoptotic cells in the submandibular glands were visualized using the Apoptag Plus Fluorescein in situ Apoptosis Detection kit (Millipore, Bedford, MA, USA), which uses terminal deoxynucleotidyl transferase dUTP nick end labeling (TUNEL) to detect DNA cleavage and chromatin condensation. Following deparaffinization and rehydration, the slides were incubated with the TUNEL reaction mixture containing TdT enzyme for $1 \mathrm{~h}$ at $37^{\circ} \mathrm{C}$, and then with anti-digoxigenin fluorescein for $30 \mathrm{~min}$ at room temperature. Nuclei were visualized using DAPI. Two blinded examiners independently counted the number of apoptotic cells in three random fields per tissue section at a magnification of $x 400$. At least three random tissue sections per gland were mounted on each slide.
Detection of cell proliferation. The Zymed proliferating cell nuclear antigen (PCNA) staining kit (Invitrogen; Thermo Fisher Scientific, Inc.) was used to detect cell proliferation. After deparaffinization, rehydration, antigen retrieval and peroxidase blocking, the slides were processed using the avidin biotin complex method for PCNA staining. Two independent observers counted the absolute number of PCNA-positive cells under a light microscope (magnification, $x 400)$ in five random fields per section. Three randomly selected sections per specimen were subjected to analysis.

Statistical analysis. Statistical analysis was performed using the Graph Pad Prism 5 package (GraphPad Software Inc., La Jolla, CA, USA). The Mann-Whitney U-test was used to determine differences between two groups, and analysis of variance was used to determine differences within the groups, followed by Tukey's honestly significant difference tests. $\mathrm{P}<0.05$ was considered to indicate a statistically significant difference.

\section{Results}

Characteristics of ADSCs and PRF. The mesenchymal stem cells used in the present study were highly purified and had CD29-positive as well as CD31- and CD34-negative immunophenotypes. Multiple differentiation capacities towards osteogenic and adipogenic lineages were also confirmed in vitro (Fig. $1 \mathrm{~A}-\mathrm{C})$. The doubling time $(2.89 \pm 0.11$ days) of cells cultured in the three-dimensional (3-D) dynamic system was significantly shorter than that of cells cultured under conventional 2-D conditions $(3.63 \pm 0.26$ days; $\mathrm{P}<0.05)$. Fluorescence microscopy and SEM revealed good adhesion and growth of stem cells on the beads (Fig. 1D). In addition, the dispersed beads began to aggregate at day 3 (Fig. 1E-a), which gradually increased at day 7 (Fig. 1E-b) and day 14 (Fig. 1E-c). After 3 weeks of culture, following the addition of microcarriers, the cells grew into visible cell clusters of 6-8 $\mathrm{mm}$ in size (Fig. 1E-d).

The blood samples were collected without anticoagulants into $10-\mathrm{ml}$ tubes and immediately centrifuged at $1,200 \mathrm{x} \mathrm{g}$ for $10 \mathrm{~min}$. The formation of fibrin clots was visible in the middle layer of each tube, between the red blood cells at the bottom and the acellular plasma at the top (Fig. 1F). The PRF clot located in the middle layer was harvested with tweezers and gently pressed onto a membrane between two sterile pieces of gauze, using soft compression for $10 \mathrm{sec}$ in order to keep the membrane wet, and the PRF membranes obtained were then prepared as described previously (Fig. 1G) (21); subsequently, the membranes were cut into fragments of a few millimeters in size and inserted into microcentrifuge tubes containing acellular plasma (Fig. 1H). Frozen sections revealed DiI-positive stem cells dispersed in the SGs of experimental mice in the IR+ADSC group (Fig. 1I), indicating the effectiveness of the intraglandular injections.

ADSCs $+P R F$ injection reverses irradiation-induced reduction in bodyweightand saliva production. Macromorphological findings at 12 weeks post transplantation demonstrated a significant reduction in body weight in the irradiated untreated mice compared with that of the non-irradiated normal mice 
A

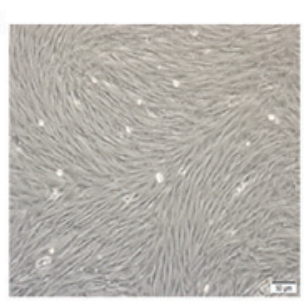

$\mathrm{Ca}$

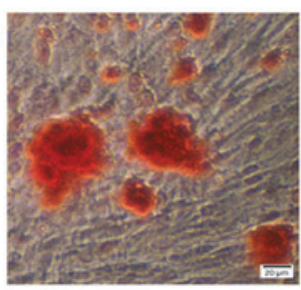

Ea

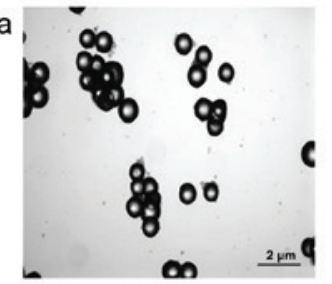

F
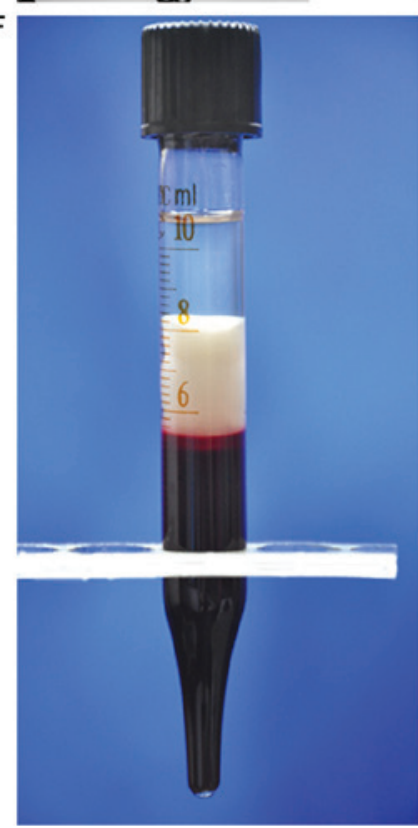

$\mathrm{Ba}$

$\mathrm{Cb}$

Eb
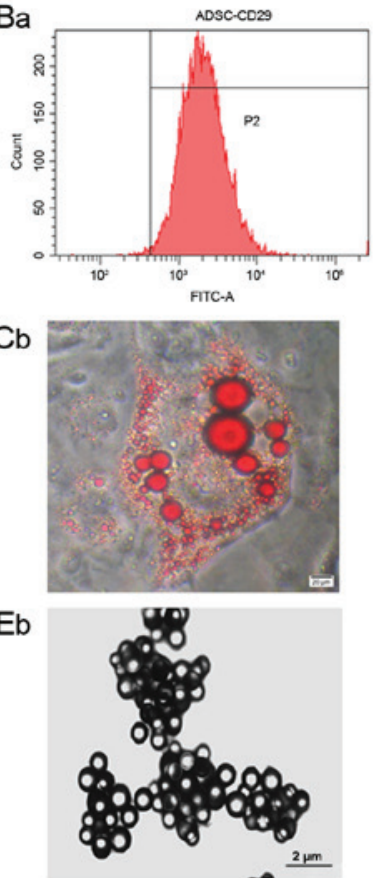

G
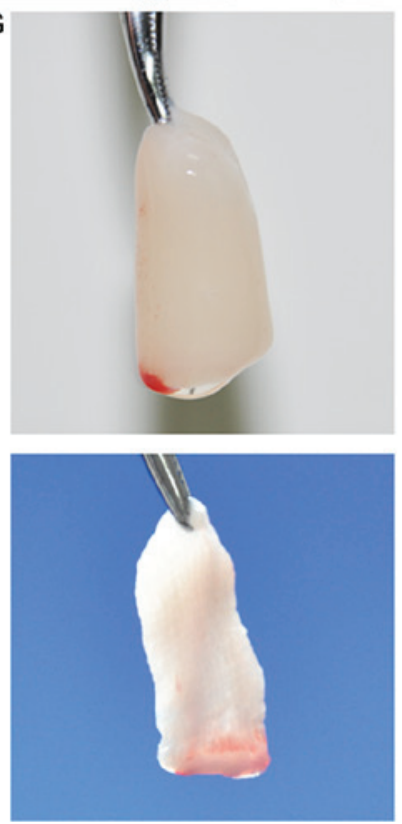

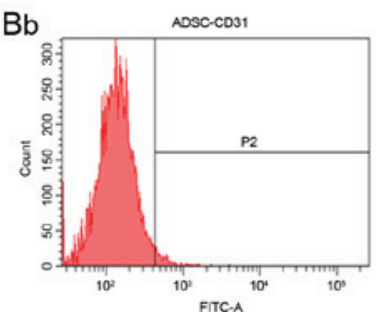

$\mathrm{Da}$

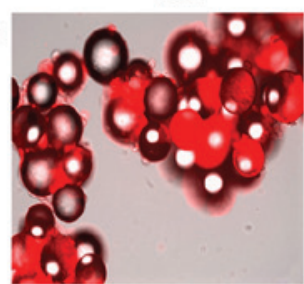

Ec

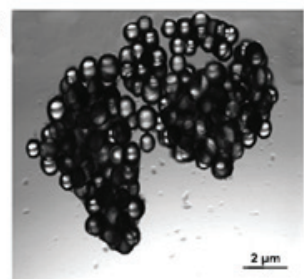

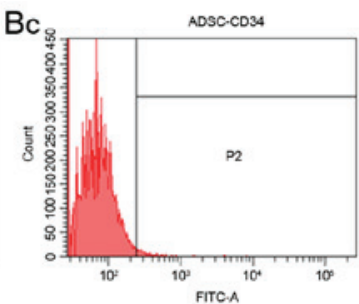

$\mathrm{Db}$

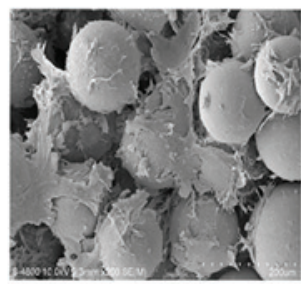

Ed

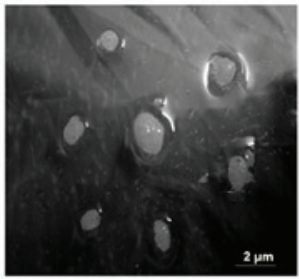

$\mathrm{H}$
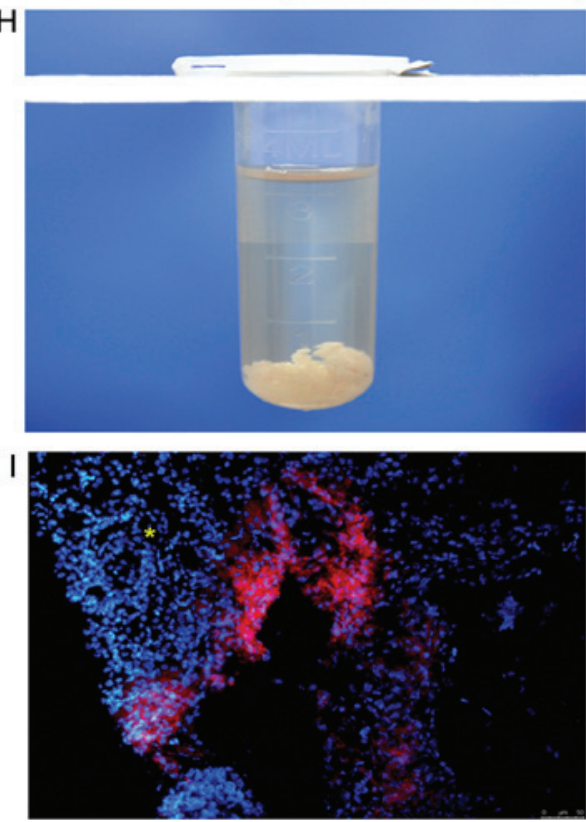

Figure 1. Preparation of ADSCs and PRFe. (A) Phase contrast micrograph of ADSCs at passage 2 (scale bar, $50 \mu \mathrm{m}$ ). (B) The cells were positive for (a) the mesenchymal stem cell marker CD29, but negative for the hematopoietic markers (b) CD31 (c) and CD34. (C) Pluripotent differentiation potentials towards (a) osteogenic and (b) adipogenic lineages were also confirmed in vitro (scale bar, $20 \mu \mathrm{m}$ ). (D-a) Fluorescence microscopy and (b) scanning electron microscopy (scale bar, $200 \mu \mathrm{m}$ ) revealed good adhesion and growth of stem cells on the microcarrier beads. (E-a) The dispersed beads began to aggregate on day 3 , with gradual increased in aggregation on (b) day 7 and (c) day 14 of culture. (d) The stem cell/bead mixture finally grew into visible cell clusters of 6-8 mm in size at 3 weeks after culture. (F) A fibrin clot is shown in the middle layer of a tube, between the red blood cells at the bottom and the acellular plasma on top. (G) The PRF clot was harvested (top panel) and the PRF membranes were obtained (bottom panel). (H) Shredded PRF membranes were immersed in microcentrifuge tubes containing acellular plasma in order to prepare the PRFe. (I) In the IR+ADSCs treatment group, DiI-positive stem cells were dispersed in the salivary glands of experimental mice. The conduit structure is indicated by a yellow asterisk. FITC, fluorescein isothiocyanate; ADSC, adipose-derived mesenchymal stem cell; PRFe, platelet-rich fibrin extract.

(23.95 \pm 3.91 vs. $34.13 \pm 4.85$ g, $\mathrm{P}<0.05$, Fig. $2 \mathrm{~A})$. In the mice injected with ADSCs, PRFe, and ADSCs combined with PRFe, the body weight was significantly increased to $32.86 \pm 3.23$, $29.98 \pm 3.73$ and $34.26 \pm 3.46 \mathrm{~g}$, respectively, compared to that in the irradiation group $(\mathrm{P}<0.05)$. Moreover, the $\mathrm{SG}$ weight at 12 weeks post transplantation was significantly increased in the ADSCs combined with PRFe group when compared to that in the irradiated untreated group $(\mathrm{P}<0.05$, Fig. $2 \mathrm{~B})$.
To determine whether the administration of ADSCs, PRFe, or ADSCs+PRFe improved the salivary secretory function, the SFR was measured at 12 weeks post transplantation. The irradiated group showed a significantly reduced ability to produce saliva $(51.51 \pm 6.97 \mu \mathrm{l} / \mathrm{min})$ when compared to the normal group (106.34 $\pm 10.57 \mu 1 / \mathrm{min}, \mathrm{P}<0.05$, Fig. $2 \mathrm{C})$. In the treatment groups, the post stimulation SFR values were all significantly increased $(\mathrm{P}<0.05$ vs. irradiation group), with those in the 
A

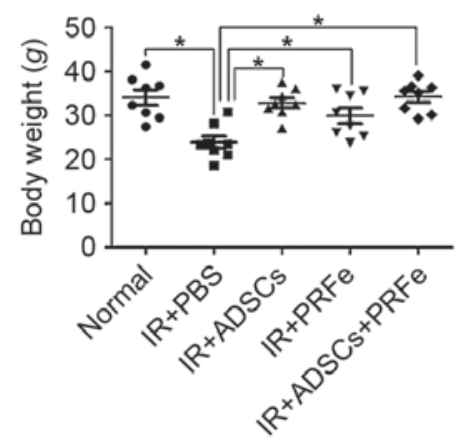

B

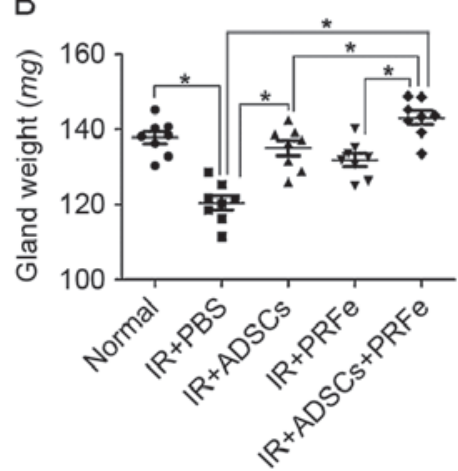

C

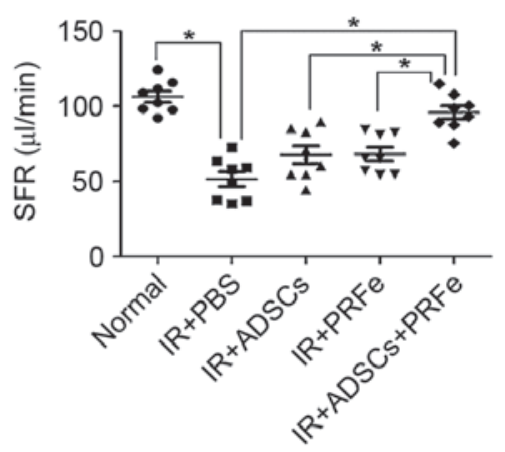

Figure 2. Macromorphological findings including (A) body and (B) salivary gland weights and (C) SFR ( $\mu 1 /$ min) at 12 weeks post transplantation. Mice transplanted with ADSCs and PRFe showed a significant increase in SFR and body weight when compared to the PBS-injected mice 12 weeks after transplantation. * $<0.05$. SFR, salivary flow rate; PBS, phosphate-buffered saline; IR, irradiation; ADSC, adipose-derived mesenchymal stem cell; PRFe, platelet-rich fibrin extract.
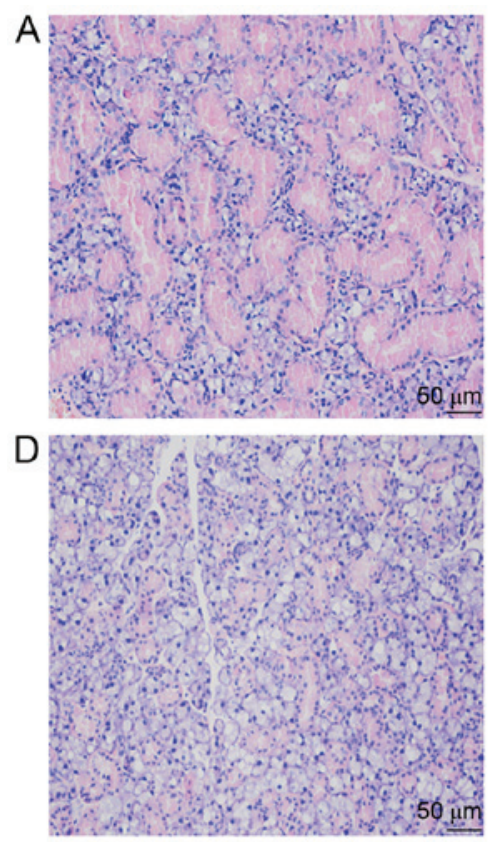
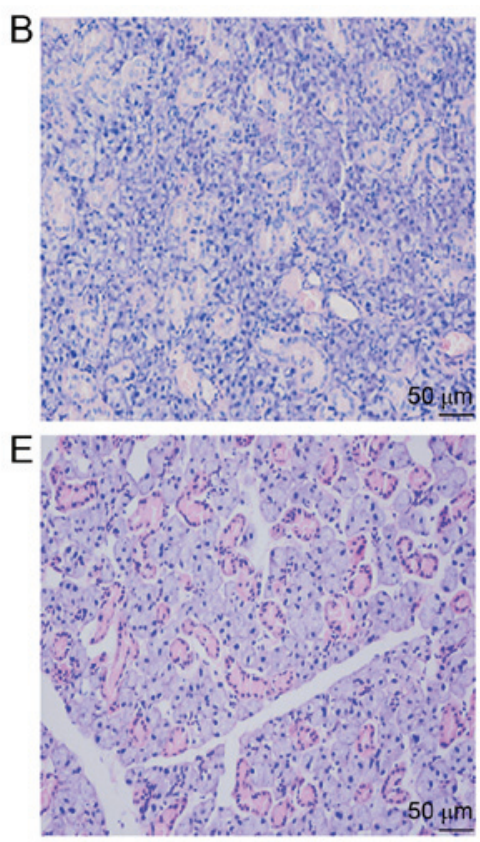

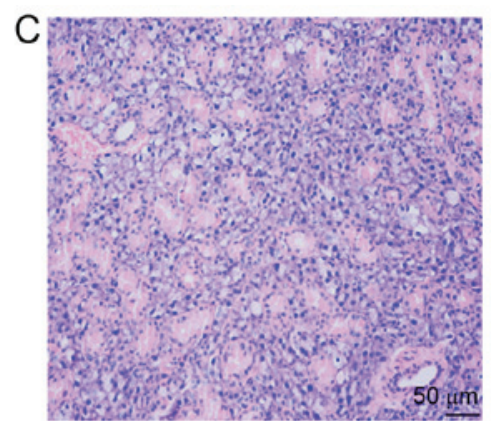

$\mathrm{F}$

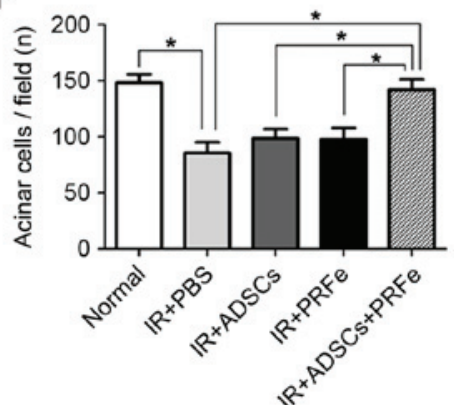

Figure 3. Micromorphological changes after irradiation were visualized by hematoxylin and eosin staining at 12 weeks post transplantation. (A-E) SGs in all treatment groups showed greater numbers of preserved structures and acini than the irradiated, untreated SGs (scale bar, $50 \mu \mathrm{m}$ ). (A) Normal group; (B) IR+PBS group; (C) IR+ADSCs group; (D) IR+PRFe group; (E) IR+ADSCs+PRFe group. (F) The ADSCs+PRFe group presented with a significantly higher number of acinar cells when compared to the irradiated group. ${ }^{*} \mathrm{P}<0.05$. PBS, phosphate-buffered saline; IR, irradiation; ADSC, adipose-derived mesenchymal stem cell; PRFe, platelet-rich fibrin extract.

ADSCs+PRFe group (98.5 $\pm 10.95 \mu \mathrm{l} / \mathrm{min})$ being significantly higher than those in the ADSC $(76.2 \pm 14.06 \mu 1 / \mathrm{min}, \mathrm{P}<0.05)$ and PRFe $(65.3 \pm 9.47 \mu 1 / \mathrm{min})$ groups $(\mathrm{P}<0.05)$.

ADSCs + PRFe injection reverses irradiation-induced changes in the micromorphology and function of SGs. Microscopic morphological changes were visualized by H\&E staining. It was revealed that at 12 weeks post transplantation, SGs in the combined treatment group presented with more preserved structures and greater numbers of acini than the irradiated and untreated SGs, while monotreatment did not markedly affect irradiation-induced structural changes (Fig. 3A-E). Quantification analysis revealed a significant reduction in the number of acinar cells in the irradiated group $(85.5 \pm 9.75$, when compared to the normal group $(148.3 .5 \pm 13.5, \mathrm{P}<0.05)$, while the number was significantly increased in the ADSCs+PRFe group (142.3 $\pm 15.6, \mathrm{P}<0.05$ vs. irradiated group) (Fig. 3F).

The results of the PAS staining were similar to those observed by H\&E staining; the number of PAS-positive acinar cells was significantly reduced in the irradiated group compared to the normal group. The ADSCs+PRFe-treated glands presented with a higher number of mucopolysaccharide-containing acinar cells than the irradiated glands $(\mathrm{P}<0.05$, Fig. 4A and B), whereas the number of PAS-positive acinar cells was not significantly affected by treatment with ADSCs or PRFe alone ( $\mathrm{P}>0.05$, Fig. 4B).

ADSCs, PRFe, and ADSCs+PRFe were found to protect several cell populations in the irradiated and treated groups. Immunohistochemistry was used to measure $\alpha$-amylase (AMY) production in the SGs in order to assess acinar function, 
A

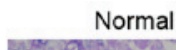

Normal

IR+PBS
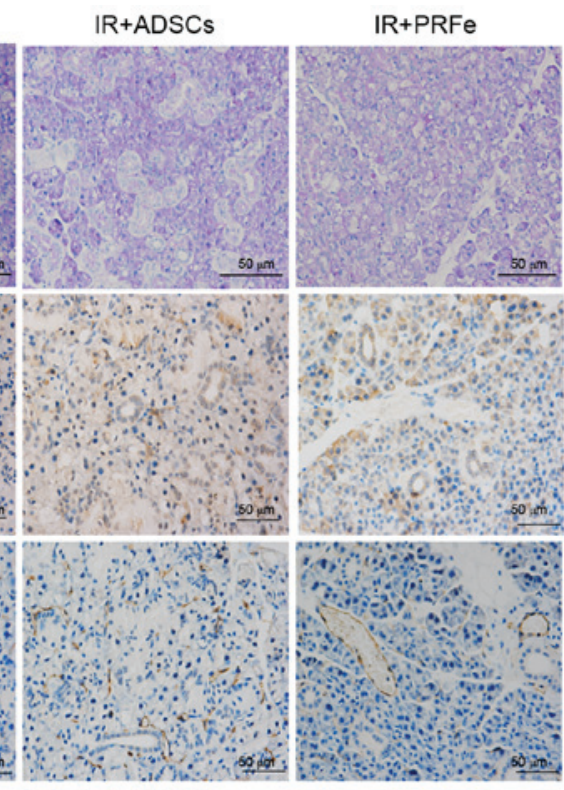

IR+ADSCs+PRFe

PAS
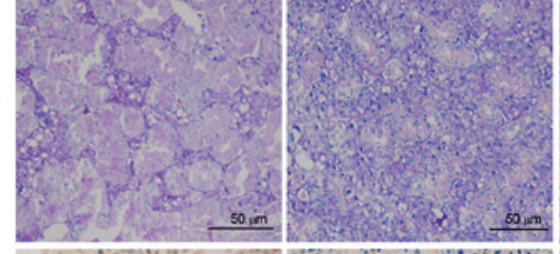

${ }_{\text {anmese }}$

CD31
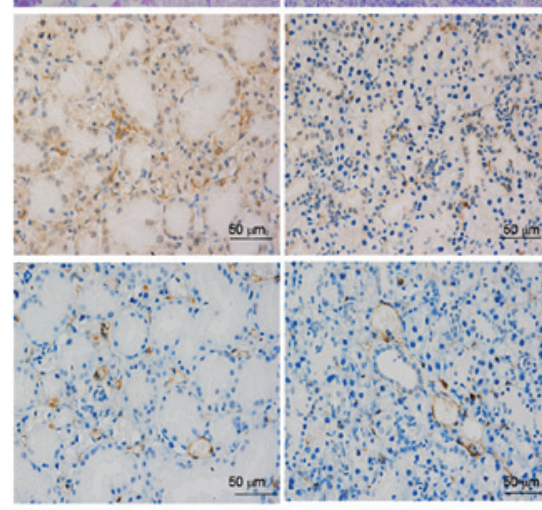

C
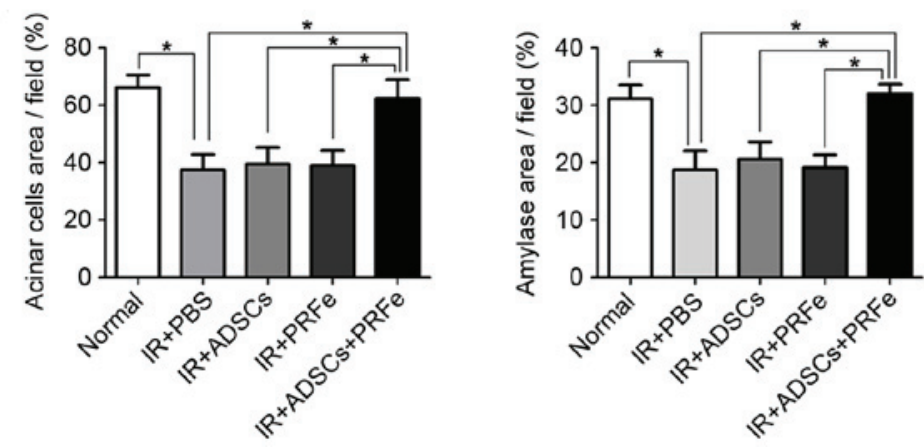

D

Figure 4. Functionalities of acinar cells at 12 weeks post transplantation. (A and B) PAS staining revealed a significant improvement in the production of mucopolysaccharides in the ADSCs+PRFe group. (A and C) AMY production was also significantly increased in this group when compared with that in the irradiated group, which was significantly less than that in the normal group. (A and D) Injection of ADSCs combined with PRFe also increased the number of microvessels when compared to that in the IR+PBS- and the IR+PRFe-treated mice (scale bar, $50 \mu \mathrm{m}$ ). ${ }^{*} \mathrm{P}<0.05$. PBS, phosphate-buffered saline; IR, irradiation; ADSC, adipose-derived mesenchymal stem cell; PRFe, platelet-rich fibrin extract; AMY, $\alpha$-amylase; PAS, Periodic acid-Schiff.

revealing significantly lower AMY levels in the irradiated SGs compared with those in the normal group $(\mathrm{P}<0.05$, Fig. 4A and $\mathrm{C}$ ). In addition, the SGs in the ADSCs+PRFe treatment group showed significantly higher levels of AMY production when compared with that in the irradiated group $(\mathrm{P}<0.05$, Fig. 4C). However, treatment with ADSC or PRFe alone did not significantly affect AMY levels compared with those in the irradiated group.

Microvessel density analysis was performed by CD31 immunostaining at 4 weeks post transplantation. The number of microvessels was found to be higher in the ADSCs+PRFe-treated mice when compared with that in the irradiation group $(\mathrm{P}<0.05$, Fig. 4D), which had the lowest microvessel density. Moreover, a significant difference in microvessel density was observed between the PRFe and the ADSCs+PRFe groups $(\mathrm{P}<0.05$, Fig. 4D). The difference between the irradiation group and the ADSCs group was also significant $(\mathrm{P}<0.05$, Fig. 4D).

In the normal group, TEM revealed a healthy cell membrane with various cytoplasmic organelles, including a large number of mitochondria and endoplasmic reticula surrounding the cell nucleui, along with the presence of the characteristic zymogen granules (Fig. 5A). By contrast, the irradiation group displayed cell disintegration, karyopyknosis and cell organelles that were evidently damaged, particularly the mitochondria, which were swollen with liquefaction, degeneration, and vacuolization (Fig. 5B). Of note, the cellular ultramicrostructure was found to be intact, except for a certain amount of mitochondrial swelling and liquefaction along with a few areas of dilatation and degeneration of the endoplasmic reticulum in the mice transplanted with ADSCs (Fig. 5C). Similar findings were observed in the PRFe group (Fig. 5D). However, no significant ultramicrostructural damage was observed in the IR+ADSCs+PRFe group. The nuclei were regularly shaped and clearly visible, a large number of mitochondria and endoplasmic reticula were present in the cytoplasm, cell organelles were intact and a large number of secretory zymogen granules were also clearly visible (Fig. 5E). Furthermore, normal, healthy, small blood vessels were also observed in the IR+ADSCs+PRFe group (Fig. 5E and F).

Protective effect of ADSCs or ADSCs combined with PRFe against irradiation-induced salivary tissue damage. The present study further explored the mechanisms responsible for the morphological and functional improvements in 
A

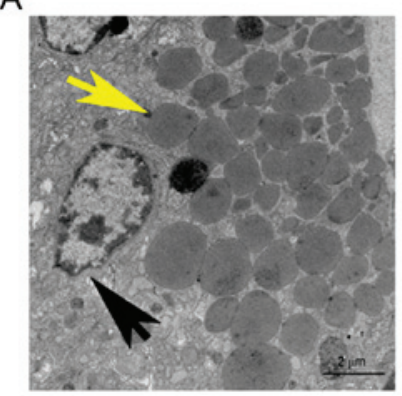

D

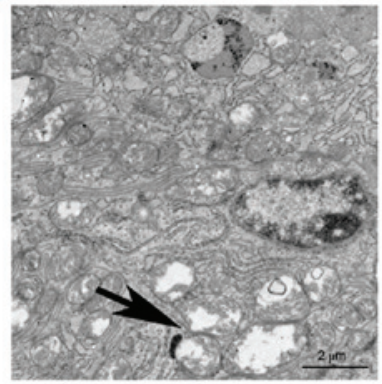

B

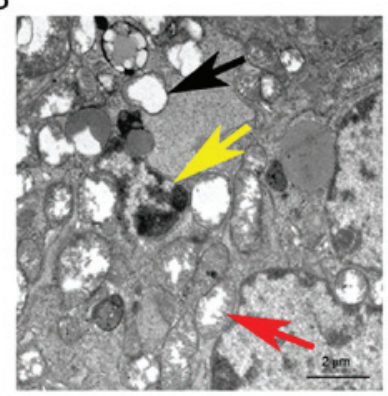

E

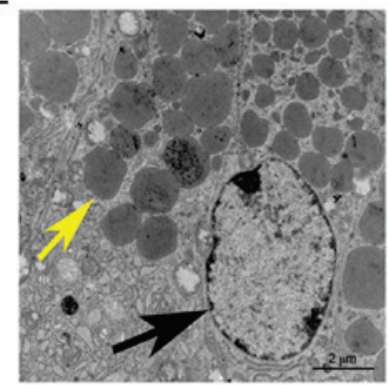

C

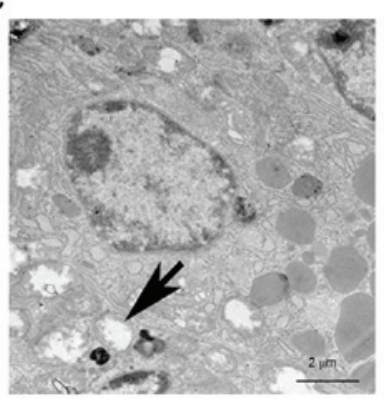

F

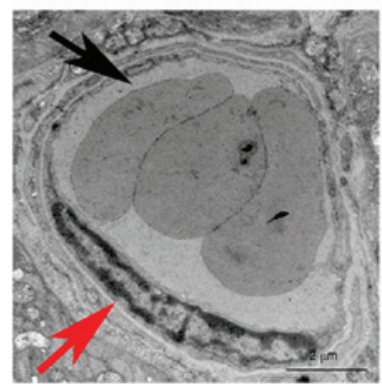

Figure 5. TEM images of salivary glands at 12 weeks after transplantation (scale bar, $2 \mu \mathrm{m}$ ). (A) TEM revealed well-maintained cell membranes in the normal group; the cell nuclei were surrounded by a large number of mitochondria and endoplasmic reticula (black arrow) and characteristic zymogen granules (yellow arrow) were present. (B) In the IR+PBS group, cell disintegration, karyopyknosis (yellow arrow) and damage to cell organelles, including swelling, liquefaction degeneration and vacuolization of the mitochondria (red and black arrows), were evident. (C) After ADSC transplantation therapy, the cell ultramicrostructure was kept intact, except for a certain amount of mitochondrial swelling and liquefaction as well as a few dilated and degenerated endoplasmic reticula (black arrow). (D) In the PRFe group, widespread intracytoplasmic vacuolization and destruction of the mitochondrial crest (black arrow) were seen. (E) No significant cell ultramicrostructural damage was observed in the IR+ADSCs+PRFe group. The cell nuclei were regular and clearly visible (black arrow), large numbers of mitochondria and endoplasmic reticula were visible in the cytoplasm, cell organelles were substantially intact and immature zymogen granules were clearly visible (yellow arrow). (F) Normal, healthy, small blood vessels were also observed in the IR+ADSCs+PRFe group; normal endothelial cells (red arrow) and erythrocytes (black arrow) are also indicated. PBS, phosphate-buffered saline; IR, irradiation; ADSC, adipose-derived mesenchymal stem cell; $\mathrm{PRFe}$, platelet-rich fibrin extract; TEM, transmission electron microscopy.

the ADSC-, PRFe- and ADSCs+PRFe-treated irradiated SGs Cell apoptosis and proliferation were analyzed by TUNEL and PCNA antibody staining, respectively. Few TUNEL-positive apoptotic cells were observed in the normal SGs, whereas significantly higher numbers were seen in the irradiated SGs $(\mathrm{P}<0.05$, Fig. 6A and $\mathrm{B})$. Administration of ADSCs combined with $\mathrm{PRFe}$ significantly reduced the number of TUNEL-positive apoptotic SG cells when compared with that in the irradiated group ( $\mathrm{P}<0.05$, Fig. 6A and $\mathrm{B}$ ). However, no significant differences between the irradiated group and the ADSC or PRFe monotreatment groups were noted $(\mathrm{P}>0.05$, Fig. 6B). PCNA staining also revealed increased proliferation in the ADSCs+PRFe group when compared with that in the irradiated group $(\mathrm{P}<0.05$, Fig. 6A and $\mathrm{C})$, while no significant effect was seen in the monotreatment groups. These results suggested that systemic transplantation of ADSCs combined with PRFe protects SGs against radiation-induced damage via inhibition of cell apoptosis and induction of cell proliferation.

\section{Discussion}

The present study showed that the intraglandular transplantation of highly homogenous ADSCs combined with heterologous PRFe was able to improve or restore the acinoductal integrity and secretory function of irradiation-induced SGs. Furthermore, the results from the present study indicated that implantation of ADSCs and PRFe can i) recover saliva production and ii) inhibit apoptosis, restore cell proliferation and regenerate the tissue.
Secretory dysfunction of SGs is inevitable, particularly after irradiation for the treatment of head and neck cancer; therefore, SG regeneration post irradiation is of utmost importance (13). Numerous studies have been performed to address this issue, including those involving the construction of tissue-engineered artificial SGs (7-10), isolation and culture of adult SG-derived stem/progenitor cells (28), reimplantation of autologous SG cells $(11,12)$ and stem cell therapy $(13,14)$. In the present study, a mouse model of irradiation-induced SG was generated according to previously described methods (22). Three months after transplantation with ADSCs combined with PRFe, the SFRs returned to near normal values in the irradiated mice, while those in the irradiated group were significantly lower. Histological examination including H\&E staining, and TEM verified that the $\mathrm{SG}$ tissues from mice subjected to irradiation were significantly damaged when compared to those in normal mice. However, the secretory functions and tissue morphologies of the SGs in the IR+ADSCs+PRFe group were restored and recovered 3 months post transplantation, indicating that the combination of ADSCs and PRFe may be used for the treatment of irradiation-damaged SGs in the clinic.

ADSCs have been widely used in numerous instances where cell therapies (via local or systemic administration) were indicated, including rheumatic disease and thyroiditis $(29,30)$. In addition, the therapeutic properties of ADSCs for the treatment of ischemic skeletal muscle and myocardial infarction have also been reported $(31,32)$. The mechanisms by which ADSCs enable the restoration of damaged tissues include cell 


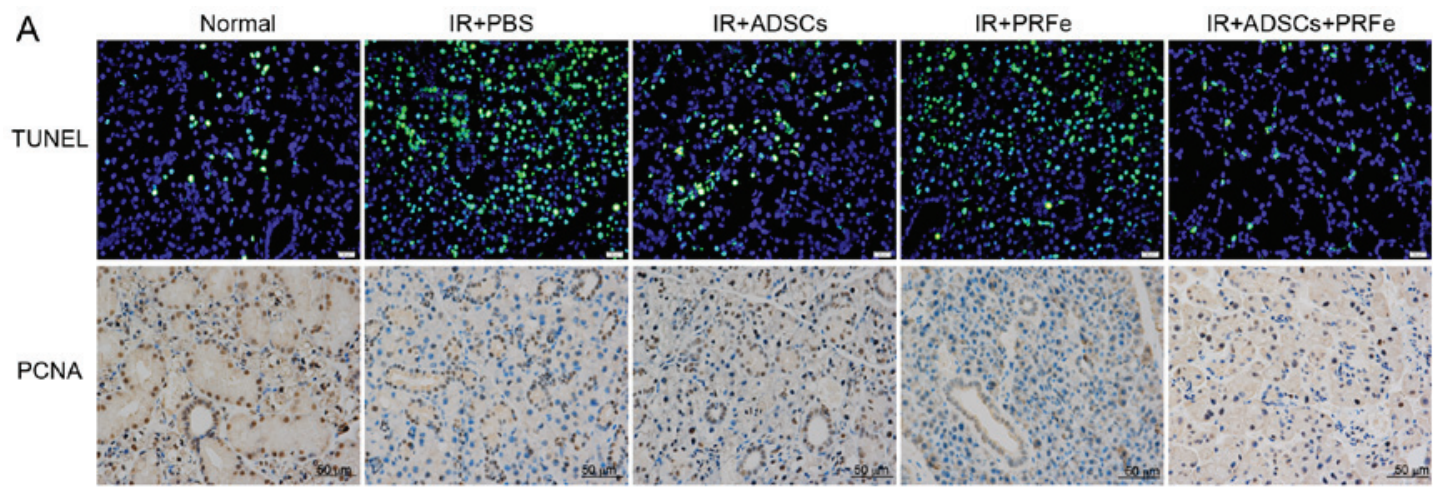

B

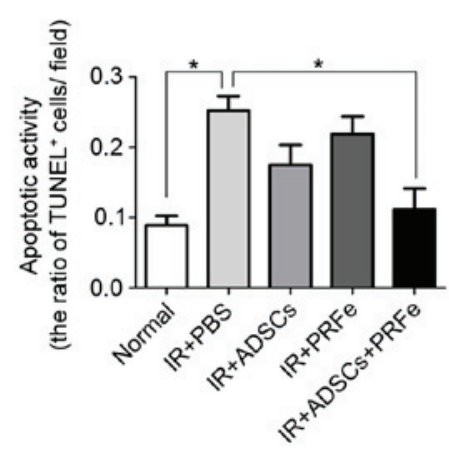

C

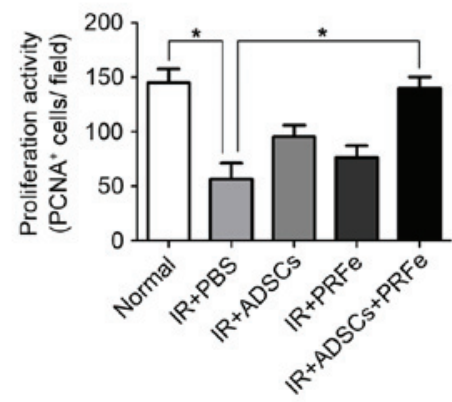

Figure 6. Protective effect of ADSCs combined with PRFe against irradiation-induced SG tissue damage at 12 weeks after transplantation. Apoptosis detection (TUNEL assay) and cell proliferation detection (PCNA assay) were performed, respectively. (A and B) Few TUNEL-positive apoptotic cells were revealed among the normal SGs, while the number was significantly increased in the irradiated SGs. ADSCs combined with PRFe administration significantly reduced the number of TUNEL-positive apoptotic cells in the IR+ADSCs+PRFe group compared with that in the the IR+PBS group. The ratio of TUNEL-positive vs. all DAPI-positive cells was calculated in random tissue sections. (A and C) The PCNA assay also revealed a higher proliferation activity in the ADSCs+PRFe group when compared to that in the irradiated group. ( $\left.{ }^{*} \mathrm{P}<0.05\right)$. PBS, phosphate-buffered saline; IR, irradiation; ADSC, adipose-derived mesenchymal stem cell; PRFe, platelet-rich fibrin extract; TUNEL, terminal deoxynucleotidyl transferase dUTP nick end labeling; PCNA, proliferating cell nuclear antigen; SG, salivary gland.

fusion, vasculogenesis, cell transdifferentiation and paracrine activities (18). A study by Kojima et al (13) confirmed that irradiation induces inflammation and apoptosis of acinar cells in SGs, leading to a decrease in blood flow and subsequent hyposalivation. ADSCs not only possess the ability to secrete angiogenic growth factors, such as vascular endothelial growth factor (VEGF) and hepatocyte growth factor, but can also differentiate into endothelial cells (13). These findings suggested that ADSCs stimulate tissue repair via paracrine activities and vasculogenesis. The results of the present study, demonstrating the role of ADSCs in treating SGs with irradiation-induced damage, are in accordance with those reported previously $(13,18)$. However, the aforementioned studies used injected cells at a concentration of $1 \times 10^{6}$ through the tail vein, whereas in the present study, mice were subjected to intra-SG injection of $2 \times 10^{5} \mathrm{ADSCs}$, as the administration of $1 \times 10^{6}$ ADSCs intraglandularly had proven fatal for the mice in preliminary experiments. In addition, in a previous study, PRF was made from $10 \mathrm{ml}$ blood so that $2 \mathrm{ml}$ of acellular plasma were obtained by blood centrifugation (21). Therefore, ADSCs were resuspended in $2 \mathrm{ml} \mathrm{PRFe}$ containing growth factors derived from PRF and acellular plasma.

ADSCs have been shown to protect SGs from irradiation-induced damage if transplanted immediately after irradiation (13). However, in the present study, a model of radiation-induced SG damage was developed that was transplanted with ADSCs combined with PRFe 3 months later. Of note, TEM, immunofluorescence, microvessel density measurements and the TUNEL assay indicated that the combination of ADSCs and PRFe provided an effective treatment outcome for the fixed damaged SGs, whereas ADSCs or PRFe alone only mildly improved the tissue morphology and functional activity. This may be attributed to the fact that the SGs in the irradiated mice had suffered severe, irreparable damage, which could not be restored by ADSCs or PRFe alone. The body weights of mice in the IR+PRFe group were increased, but the gland weight and SFR did not. These results may be due to the protective efficacy of growth factors derived from PRFe on mice. PRFe alleviated the irradiation-induced damage in the mice, but failed to restore SG structure and function. However, the administration of ADSCs combined with PRFe successfully restored the severely damaged SGs by providing it with large quantities of stem cells as well as growth factors, including such as platelet-derived growth factor, transforming growth factor-beta 1, insulin-like growth factor-1, VEGF, endothelial cell growth factor and fibroblast growth factor-2 $(19,21)$. As the efficacy of ADSCs alone was similarly limited, it is indicated that growth factors are important for regeneration, based on the finding that ADSCs and PRFe appeared to have synergistic effects. A previous study showed that MSCs could adopt a salivary epithelial phenotype by mesenchymal-to-epithelial transition induced by crosstalk between cells and the microenvironment (33). Therefore, with the addition of PRFe, it is more likely that the vasculogenic and paracrine effects of ADSCs, rather than their transdifferentiation potential, are responsible for the functional restoration of 
the SGs via neovascularization, as well as by increasing acinar cell survival and decreasing apoptosis. To the best of our knowledge, the present study was the first to demonstrate the functional restoration of permanent irradiation-induced SG damage by intraglandular transplantation of ADSCs combined with PRFe. However, further studies are warranted to expound the process by which the combination of ADSCs and PRFe mediates $\mathrm{SG}$ regeneration.

Research efforts to provide a safe and reliable method for MSC infusion has led to the development of systemic cell administration for the treatment of various types of disease (34). Moreover, Kojima et al (13) have demonstrated that transplantation of allogenic ADSCs is nontoxic and safe. In the present study, ADSCs were cultured and expanded using the 3-D cell culture method based on the rotating cell culture bioreactor, which is an acceptable III-D dynamic culture system for cell growth and differentiation, as it aids in increasing the diffusion of nutrients and oxygen, thereby promoting cell viability and proliferation (35). In addition, in the present study, xenogenic PRFe was successfully transplanted into the SGs of mice without any signs of toxicity at doses of $2 \times 10^{5}$ cells. PRFe provided growth factors in combination with the ADSCs to remedy the irradiation-induced SG damage and also to restore the SGs' secretory function. However, while xenogenic models are beneficial, their outcomes are controversial. PRFe contains a variety of growth factors and has no cellular components due to the centrifugation and filtration steps during its preparation; therefore, it cannot cause any immunological rejection. In the present study, xenogenicity did not hinder the effect of ADSCs and PRFe on the SG cells. However, in the present study, the immune evasion strategies of the xenogenic PRFe were presumed to be associated with the immune-privileged properties of stem cells, such as the modulation of immune cell function, hypoimmunogenicity and the creation of a suppressive microenvironment (36).

Several issues require addressing prior to using ADSCs in combination with PRFe for the functional restoration of SGs with fixed, irradiation-induced damage. First, a preclinical animal model suitable for evaluating the therapeutic potential of human stem cells combined with PRFe transplantation should be established. Second, the ideal number of stem cells and the amount of PRFe transplanted must be determined. Third, appropriate routes of transplantation, including intravenous injection, intraglandular transplantation by percutaneous injection and retroductal administration via an excretory duct should be confirmed. Finally, the basic mechanism of SG regeneration mediated by ADSCs combined with PRFe should be elucidated. The method described in the present study may be useful for preclinical research purposes and can be used to protect as well as to restore the structure and secretory function of SGs after irradiation-induced damage.

In conclusion, the present study was the first to use a 3-D dynamic cell culture method to obtain a large number of ADSCs in order to meet the required number of cells for transplantation. Allogenic ADSCs combined with xenogenic PRFe, directly transplanted into SGs with permanent, irradiation-induced damage, were able to ameliorate salivary hypofunction. Furthermore, the combination of ADSCs and PRFe offered an effective treatment outcome for irradiation-induced SG damage when compared to ADSCs or PRFe alone. Thus, the combination of ADSCs and PRFe should be regarded as novel mode of cell-based therapy for the restoration of irradiation-induced SG damage and hypofunction.

\section{Acknowledgements}

The present study was funded by the National Natural Science Foundation of China (no. 31170942).

\section{References}

1. Pedersen AM, Bardow A, Jensen SB and Nauntofte B: Saliva and gastrointestinal functions of taste, mastication, swallowing and digestion. Oral Dis 8: 117-129, 2002.

2. Vissink A, Burlage FR, Spijkervet FK, Jansma J and Coppes RP: Prevention and treatment of the consequences of head and neck radiotherapy. Crit Rev Oral Biol Med 14: 213-225, 2003.

3. Jensen SB, Pedersen AM, Vissink A, Andersen E, Brown CG, Davies AN, Dutilh J, Fulton JS, Jankovic L, Lopes NN, et al: A systematic review of salivary gland hypofunction and xerostomia induced by cancer therapies: Prevalence, severity and impact on quality of life. Support Care Cancer 18: 1039-1060, 2010.

4. Chambers MS, Garden AS, Kies MS and Martin JW: Radiationinduced xerostomia in patients with head and neck cancer: Pathogenesis, impact on quality of life, and management. Head Neck 26: 796-807, 2004.

5. Zheng C, Cotrim AP, Rowzee A, Swaim W, Sowers A, Mitchell JB and Baum BJ: Prevention of radiation-induced salivary hypofunction following hKGF gene delivery to murine submandibular glands. Clin Cancer Res 17: 2842-2851, 2011.

6. Arany S, Benoit DS, Dewhurst S and Ovitt CE: Nanoparticlemediated gene silencing confers radioprotection to salivary glands in vivo. Mol Ther 21: 1182-1194, 2013.

7. Yang TL and Young TH: The enhancement of submandibular gland branch formation on chitosan membranes. Biomaterials 29: 2501-2508, 2008.

8. Soscia DA, Sequeira SJ, Schramm RA, Jayarathanam K, Cantara SI, Larsen M and Castracane J: Salivary gland cell differentiation and organization on micropatterned PLGA nanofiber craters. Biomaterials 34: 6773-6784, 2013.

9. Joraku A, Sullivan CA, Yoo J and Atala A: In-vitro reconstitution of three-dimensional human salivary gland tissue structures. Differentiation 75: 318-324, 2007.

10. Jean-Gilles R, Soscia D, Sequeira S,Melfi M, Gadre A, Castracane J and Larsen M: Novel modeling approach to generate a polymeric nanofiber scaffold for salivary gland cells. J Nanotechnol Eng Med 1: 31008, 2010.

11. Nanduri LS, Lombaert IM, van der Zwaag M, Faber H, Brunsting JF, van Os RP and Coppes RP: Salisphere derived

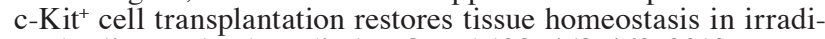
ated salivary gland. Radiother Oncol 108: 458-463, 2013.

12. Lombaert IM, Brunsting JF, Wierenga PK, Faber H, Stokman MA, Kok T, Visser WH, Kampinga HH, de Haan G and Coppes RP: Rescue of salivary gland function after stem cell transplantation in irradiated glands. PLoS One 3: e2063, 2008.

13. Kojima T, Kanemaru S, Hirano S, Tateya I, Ohno S, Nakamura T and Ito J: Regeneration of radiation damaged salivary glands with adipose-derived stromal cells. Laryngoscope 121: 1864-1869, 2011.

14. Lim JY, Yi T, Choi JS, Jang YH, Lee S, Kim HJ, Song SU and Kim YM: Intraglandular transplantation of bone marrow-derived clonal mesenchymal stem cells for amelioration of post-irradiation salivary gland damage. Oral Oncol 49: 136-143, 2013.

15. Matsumoto S,Okumura K, Ogata A,Hisatomi Y,Sato A, HattoriK, Matsumoto M, Kaji Y, Takahashi M, Yamamoto T, et al: Isolation of tissue progenitor cells from duct-ligated salivary glands of swine. Cloning Stem Cells 9: 176-190, 2007.

16. Tran SD, Liu Y, Xia D, Maria OM, Khalili S, Wang RW, Quan VH, $\mathrm{Hu} \mathrm{S}$ and Seuntjens J: Paracrine effects of bone marrow soup restore organ function, regeneration, and repair in salivary glands damaged by irradiation. PLoS One 8: e61632, 2013.

17. Gomillion CT and Burg KJ: Stem cells and adipose tissue engineering. Biomaterials 27: 6052-6063, 2006.

18. Lim JY, Ra JC, Shin IS, Jang YH, An HY, Choi JS, Kim WC and Kim YM: Systemic transplantation of human adipose tissue-derived mesenchymal stem cells for the regeneration of irradiation-induced salivary gland damage. PLoS One 8: e71167, 2013. 
19. Dohan DM, Choukroun J, Diss A, Dohan SL, Dohan AJ, Mouhyi J and Gogly B: Platelet-rich fibrin (PRF): A second-generation platelet concentrate. Part I: Technological concepts and evolution. Oral Surg Oral Med Oral Pathol Oral Radiol Endod 101: e37-e44, 2006.

20. Sunitha Raja V and Munirathnam Naidu E: Platelet-rich fibrin: Evolution of a second-generation platelet concentrate. Indian J Dent Res 19: 42-46, 2008.

21. Liu B, Tan XY, Liu YP, Xu XF, Li L, Xu HY, An R and Chen FM: The adjuvant use of stromal vascular fraction and platelet-rich fibrin for autologous adipose tissue transplantation. Tissue Eng Part C Methods 19: 1-14, 2013.

22. Sumita Y, Liu Y, Khalili S, Maria OM, Xia D, Key S, Cotrim AP, Mezey E and Tran SD: Bone marrow-derived cells rescue salivary gland function in mice with head and neck irradiation. Int J Biochem Cell Biol 43: 80-87, 2011.

23. Zwezdaryk KJ, Warner JA, Machado HL, Morris CA and Höner zu Bentrup K: Rotating cell culture systems for human cell culture: Human trophoblast cells as a model. J Vis Exp: pii: 3367, 2012.

24. Li P, Zhang Y, Wang YM, Duan CM, Hao T, Wu BL and Wang CY: RCCS enhances EOE cell proliferation and their differentiation into ameloblasts. Mol Biol Rep 39: 309-317, 2012.

25. Picken MM: Options for amyloid typing in renal pathology: The advantages of frozen section immunofluorescence and a summary of general recommendations regarding immunohistochemistry methods. In: Amyloid and Related Disorders. Current Clinical Pathology. Picken M, Herrera G and Dogan A (eds). Humana Press, New York, NY, pp283-293, 2015.

26. Li Z, Wang Y, Xing HY, Wang Z, Hu H, An R, Xu H, Liu Y and Liu B: Protective efficacy of intravenous transplantation of adipose-derived stem cells for the prevention of radiation-induced salivary gland damage. Arch Oral Biol 60: 1488-1496, 2015.

27. Weidner N, Semple JP, Welch WR and Folkman J: Tumor angiogenesis and metastasis-correlation in invasive breast carcinoma N Engl J Med 324: 1-8, 1991.

28. Baek H, Noh YH, Lee JH, Yeon SI, Jeong J and Kwon H: Autonomous isolation, long-term culture and differentiation potential of adult salivary gland-derived stem/progenitor cells. J Tissue Eng Regen Med 8: 717-727, 2014.
29. Zhou B, Yuan J, Zhou Y, Ghawji M Jr, Deng YP, Lee AJ, Lee AJ, Nair U, Kang AH, Brand DD and Yoo TJ: Administering human adipose-derived mesenchymal stem cells to prevent and treat experimental arthritis. Clin Immunol 141: 328-337, 2011.

30. Choi EW, Shin IS, Lee HW, Park SY, Park JH, Nam MH, Kim JS, Woo SK, Yoon EJ, Kang SK, et al: Transplantation of CTLA4Ig gene-transduced adipose tissue-derived mesenchymal stem cells reduces inflammatory immune response and improves Th1/Th2 balance in experimental autoimmune thyroiditis. J Gene Med 13: 3-16, 2011.

31. Zhang DZ, Gai LY, Liu HW, Jin QH, Huang JH and Zhu XY: Transplantation of autologous adipose-derived stem cells ameliorates cardiac function in rabbits with myocardial infarction. Chin Med J (Engl) 120: 300-307, 2007.

32. Shevchenko EK, Makarevich PI, Tsokolaeva ZI, Boldyreva MA Sysoeva VY, Tkachuk VA and Parfyonova YV: Transplantation of modified human adipose derived stromal cells expressing VEGF165 results in more efficient angiogenic response in ischemic skeletal muscle. J Transl Med 11: 138, 2013.

33. Maria OM and Tran SD: Human mesenchymal stem cells cultured with salivary gland biopsies adopt an epithelial phenotype. Stem Cells Dev 20: 959-967, 2011.

34. Kang SK, Shin IS, Ko MS, Jo JY and Ra JC: Journey of mesenchymal stem cells for homing: Strategies to enhance efficacy and safety of stem cell therapy. Stem Cells Int 2012: 342968, 2012.

35. Lei X, Deng Z, Zhang H, Zhao H, Zhou J, Liu S, Chen Q, Ning L, Cao Y, Wang X, et al: Rotary suspension culture enhances mesendoderm differentiation of embryonic stem cells through modulation of Wnt/ $\beta$-catenin pathway. Stem Cell Rev 10: 526-538, 2014.

36. Ryan JM, Barry FP, Murphy JM and Mahon BP: Mesenchymal stem cells avoid allogeneic rejection. J Inflamm (Lond) 2: 8, 2005 .

This work is licensed under a Creative Commons Attribution-NonCommercial-NoDerivatives 4.0 International (CC BY-NC-ND 4.0) License. 